\title{
A numerical investigation and experimental verification of size effects in loaded bovine
} cortical bone

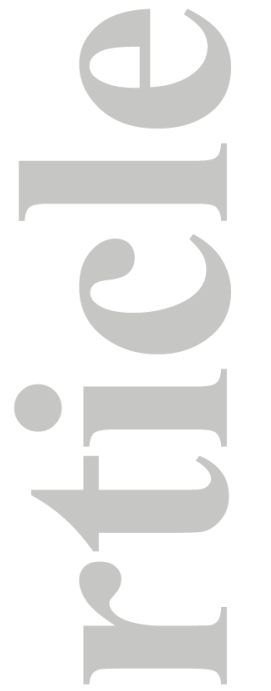

\author{
J.C. Frame ${ }^{1}$, M.A. Wheel ${ }^{2}$ \& P.E. Riches ${ }^{1}$ \\ ${ }^{1}$ Department of Biomedical Engineering \\ University of Strathclyde \\ Glasgow, G4 0NW, UK \\ ${ }^{2}$ Department of Mechanical and Aerospace Engineering \\ University of Strathclyde \\ Glasgow, G1 1XJ, UK \\ marcus.wheel@strath.ac.uk \\ Tel +441415483307 \\ Fax +44 1415525105
}

\begin{abstract}
In this paper we present two and three dimensional finite element based numerical models of loaded bovine cortical bone that explicitly incorporate the dominant microstructural feature: the vascular channel or Haversian canal system. The finite element models along with the representation of the microstructure within them are relatively simple: two dimensional models, consisting of a structured mesh of linear elastic planar elements punctuated by a periodic distribution of circular voids, are used to represent beam samples of cortical bone in which the channels are orientated perpendicular to the sample major axis, while three dimensional models, employing a corresponding mesh of equivalent solid elements, represent those samples in which the canals are aligned with the axis. However, these models are exploited in an entirely novel approach involving the representation of material samples of different sizes and surface morphology. The numerical results obtained for the virtual material samples when loaded in bending indicate that they exhibit size effects not forecast by either classical (Cauchy) or more generalized elasticity theories. However, these effects are qualitatively consistent with those that we observed in a series of carefully conducted experiments involving the flexural testing of bone samples of different sizes. Encouraged by this qualitative agreement we have identified appropriate model parameters, primarily void volume fraction but also void separation and matrix modulus by matching the computed size effects to those we observed experimentally. Interestingly, the parameter choices that provide the most suitable match of these effects broadly concur with those we actually observed in cortical bone.
\end{abstract}

This article has been accepted for publication and undergone full peer review but has not been through the copyediting, typesetting, pagination and proofreading process which may lead to differences between this version and the Version of Record. Please cite this article as doi: $10.1002 / \mathrm{cnm} .2903$ 


\section{Keywords:-}

Cortical bone; mechanical behaviour; size effect; finite element analysis; generalized continuum; micropolar (Cosserat) elasticity

\section{Introduction}

Cortical bone is a heterogeneous material with fibrous, porous and particulate phases combining to form a complex hierarchical microstructure. The microstructure associated with porous features, such as vascular channels, may have contributing influences to the stress concentrations and stress shielding around implants [1,2,3], yet the importance of these channels in the mechanical behaviour of cortical bone is not well understood. The design and integration of an implant and understanding of the bone-prosthesis interface are important factors in prosthetic design $[4,5,6,7]$, but the interaction between prosthesis and cortical bone at a fundamental microstructural level is relatively poorly understood $[8,9,10]$. It is proposed that if one can characterise how the heterogeneity in the microstructure affects the macroscale stress, particularly periprosthetically, this may herald a greater potential for innovative, longer lasting prostheses designs.

Heterogeneous materials may be modelled using multiscale modelling, which represents the global behaviour of a heterogeneous material by firstly developing a representative volume element (RVE) that incorporates microstructural detail at the scale of interest $[11,12,13,14$, $15,16,17]$. After applying homogeneous boundary conditions the mechanical response of the RVE can then be used to identify the constitutive parameters in homogenised, Cauchy type continuum representations of the material. However, homogenization may result in the suppression of microstructure dependent mechanical behaviour such as the dependence of stiffness on size. This is usually of little consequence when the scale of the microstructure is small compared to the overall scale but when they are comparable then this may be more significant. Alternative, more generalized continuum theories therefore attempt to intrinsically embrace or incorporate such behaviour. One such theory, micropolar (or Cosserat) elasticity, incorporates an independent rotation as an additional degree of freedom along with additional constitutive constants [18, 19]. One such constant, the characteristic length, reflects the size scale associated with the underlying structure of a heterogeneous material $[20,21,22,23,24,25]$. Furthermore, a size dependence of flexural stiffness or rigidity is explicitly forecast.

Whilst the mechanical behaviour of homogeneous materials is size independent, this is not necessarily so, macroscopically, for heterogeneous materials. Size effects have been observed in polymeric foams [26, 27, 28], naturally occurring materials, notably cortical bone [29, 30], and materials consisting of arrays of periodic voids [23, 24, 25]. Generalized continuum theories like Cosserat (micropolar) elasticity predict a size effect in which flexural stiffness increases as the size of geometrically similar material samples reduces, while uniaxial stiffness under uniform tensile or compressive loading remains size independent, as in the Cauchy case. In the case of slender rectangular beam samples loaded in three point bending, 
micropolar elasticity theory predicts that the flexural stiffness, $K$, increases linearly with decreasing sample size as measured by the reciprocal of beam depth squared [23] according $K=4 E^{*} b\left(\frac{d}{L}\right)^{3}\left[1+\left(\frac{l_{c}}{d}\right)^{2}\right]$

where $E^{*}$ may be considered to be a flexural modulus, $L$ is the supported sample span, $b$ and $d$ are the breadth and depth of the cross section, and $l_{c}$ is a characteristic length parameter thought to reflect the size scales associated with the underlying material microstructure. The conventional micropolar characteristic length in bending, $l_{b}$, is related to $l_{c}$, in (1) by $l_{b}=$ $l_{c} / \sqrt{24}[23]$.

Experimentally, the flexural rigidity of cortical bone has been shown to increase with decreasing sample size [29] or conversely, decrease with reducing sample size [30]. Thus, contradictory observations of size effects have been reported previously in the literature. In the earlier work [29] sample size range was more limited than in the later work [30] which extended this range down to much smaller sizes where such effects may be more pronounced. However, in the later work the decrease in flexural stiffness with reducing sample size was interpreted in the framework of Cauchy elasticity, with the flexural modulus being identified as supposedly size dependent, rather than in the context of more generalized elasticity theories which incorporate a constant modulus and account for any size dependency through the additional length scale parameter. Surface influences, such as roughness or damage, have also been suggested as possible compromising factors in experimentally identifying size effects [28] but these have not been systematically investigated or related to the effects actually observed. An analytical attempt to explain the source of unanticipated size effects in heterogeneous materials including cortical bone has recently been provided using the analogue of a laminated beam comprised of alternating stiff and compliant layers [31].

Resolving the previously reported contradictions is the primary motivation for the present work. This paper therefore addresses the fundamental question of whether bone may be considered a generalized continuum. Results from three-point bending experiments from mid-diaphyseal bovine femur cortical bone samples of varying size are compared to FE models of beam samples with transversely and axially aligned microstructural detail comprised of tubular channels and two distinct surface morphologies: one which is smooth and one in which the channels are evident on the surface. Both cases are investigated numerically since the morphology of the actual samples is unknown beforehand. In comparing numerical predictions and experimental results, not only do we derive the characteristic length of cortical bone in femoral longitudinal and radial directions, but we highlight the influence of surface morphology in characterising size-effect behaviour in heterogeneous materials more generally.

\section{Finite Element Representations of Cortical Bone}

This article is protected by copyright. All rights reserved. 


\subsection{Material Representation}

We numerically investigate the mechanical behaviour of an idealised representation of cortical bone comprised of a solid matrix phase that is punctuated by unidirectional tubular voids of circular cross section, the centres of which are located on a regular, equilateral triangular array (Figure 1a). This particular arrangement enables the matrix to be represented straightforwardly by meshes that can be generated by replication of a unit cell comprised of a structured array of elements. While it would be possible to base mesh generation on images of actual cortical bone samples obtained by scanning, the more random distribution in both void diameter and location obtained from the images would necessitate the use of unstructured meshes which would in turn severely compromise computational efficiency. The tubular voids represent the aforementioned predominant porous microstructural feature, the vascular channel system. Other smaller scale features that comprise the complex microstructural hierarchy of cortical bone are not included in this idealised representation. This representation is thus distinctly different from other recent idealisations of bone which are typically assembled upwards from the smallest microstructural scale [32, 33]. The assumed unidirectional orientation of the voids is consistent with the channel alignment observed in the cortical bone layer of the mid diaphysis section of long bones such as the femur. The matrix material was assumed to be isotropic, although in reality the matrix is known to be anisotropic due to hydroxyapatite and collagen fibre orientations. This necessary assumption of matrix isotropy reduces modelling complexity by minimizing the number of constitutive parameters that need to be specified and will entirely attribute any observed anisotropy to void orientation rather than matrix anisotropy.

\subsection{Two Dimensional Finite Element Models of Virtual Samples of Idealised Material with}

\section{Transversely Orientated Voids}

The geometry of the representative material is described by the void radius, $V_{R}$, and the separations of the void centres in the $\mathrm{x}$ and $\mathrm{y}$ directions, $S_{\mathrm{x}}$ and $S_{\mathrm{y}}$, respectively, noting $S_{y}=\sqrt{3} S_{x} / 2$ (Figure $1 b$ ). The void volume fraction, $V_{f}$, is readily derived. Initially the separation, $\mathrm{S}_{\mathrm{X}}$, was nominally prescribed as $1.0 \mathrm{~mm}$ and since the matrix material was assumed to be isotropic it was defined by just its Young's modulus and Poisson's ratio of 20 GPa and 0.3 respectively $[34,35,36]$.

Two dimensional finite element meshes were used to represent beam like test samples of the representative material in which the channels were orientated transverse to both the sample major and minor axes. To generate these meshes two different unit cells were first created (Figures 2a, and 2b). Linear elastic, eight noded quadratic quadrilateral elements were used in generating the unit cells. The unit cells were then regenerated at periodic spatial increments to create entire virtual beam samples of four different sizes (Figures 2c and 2d) and two surface morphology variants (Figures $2 \mathrm{c}$ and $2 \mathrm{~d}$ ). Sample size was determined by the number of rows of voids across the section which varied from one to four. Initially, virtual samples of three different void fractions varying from around $3 \%$ to over $30 \%$, thereby covering the 
entire range likely to be seen in cortical bone $[37,38,39,40]$, were generated by prescribing $\mathrm{V}_{\mathrm{R}}$ as appropriate. These samples were then suitably constrained and loaded in uniform uniaxial compression along the sample major axis. The effective Young's modulus was determined from the ratio of the applied compressive stress to the global strain. Equivalent samples were then created by interchanging $S_{X}$ and $S_{Y}$ and similarly loaded to assess the level of planar anisotropy exhibited by the representative material.

Further virtual beams of five different volume fractions, the three values considered previously together with two further intermediate values, were then generated in two different length to depth $(\mathrm{L} / \mathrm{d})$ aspect ratios: 10.4:1 and 20.8:1, at each of the four sizes and both surface morphologies. These were all loaded in 3 point bending to identify any size effects in their flexural stiffness and the possible dependence of these effects on surface morphology. The vertical displacement at a point near one end of the lower surface was constrained and a point load applied at the intersection of the upper surface and the sample central symmetry plane forming the other end of the mesh (Figure 2c and 2d). Both the constraint and load were carefully positioned between neighbouring voids to minimize any localized deformation that might be incurred in placing them directly adjacent to particular voids. The horizontal displacements of all nodes on the symmetry plane were also constrained (Figure $2 \mathrm{c}$ and $2 \mathrm{~d}$ ). Beam flexural stiffness was determined by dividing twice the applied point load by the average vertical displacement of all nodes located on the symmetry plane. Satisfactory convergence of the average vertical displacement was achieved for all void volume fractions investigated using just four or five element divisions between the void surface and unit cell boundary as illustrated in Figures 2(a) and (b).

2.3 Three Dimensional Finite Element Models of Virtual Samples of Idealised Material with Axially Aligned Voids

Representation of beam samples of the idealized material in which the voids were aligned parallel to the major axis rather than transverse to it necessitated the use of three dimensional FE meshes. These meshes were generated by firstly repeatedly replicating the unit cell meshes (figures $2 \mathrm{a}$ and $2 \mathrm{~b}$ ) to provide a two dimensional mesh representing the cross section of the virtual sample (figures $3 \mathrm{a}$ and $3 \mathrm{c}$ ) and then extruding these 2D meshes in the direction of the sample major axis until the sample length was realised (Figures $3 \mathrm{~b}$ and $3 \mathrm{~d}$ ). Higher order hexahedral elements with 20 nodes were used to represent the idealised material matrix which due to the assumption of isotropy, was assigned the previously prescribed properties. The axial dimension of the elements was selected to ensure that the aspect ratio of any individual element did not exceed 3. This procedure was used to generate FE meshes of virtual samples of varying sizes, surface morphology (figures $3 \mathrm{~b}$ and $3 \mathrm{~d}$ ) and void volume fraction matching those of the corresponding 2D samples. These meshes were firstly loaded uniaxially, parallel to the channels, and subsequently in three point bending. Symmetries about the vertical plane corresponding to the mid length cross section and the perpendicular, axially aligned vertical plane(figures $3 \mathrm{a}$ and $3 \mathrm{c}$ ) were exploited in both loading cases through the application of suitable displacement constraints to minimize overall computational effort. The modulus in the major axis direction was again determined from the axial load and the 
resulting axial extension while the flexural stiffness was found from the centrally applied load and the average displacement of all nodes on the mid length cross section in the direction of this load. As was found with the two dimensional models, converged solutions for this average displacement and thus for the flexural stiffness were obtained using just four or five element divisions between the void surface and the boundary of the unit cell (figures $3 b$ and $3 d)$.

\section{Experimental Testing of Bovine Cortical Bone}

Experimental 3-point bending tests on cortical bone specimens were performed concurrently with the numerical modelling. Extensive literature on the compressive strength of cortical bone currently exists for comparison with the axial numerical results, however to provide a direct comparison with the numerical bending simulations 3-point bending experiments were required to provide the necessary insight into microstructural size effects. Five bovine femurs were first obtained from a local abattoir and frozen at $-20{ }^{\circ} \mathrm{C}$ until required. The middiaphysis section was used for extracting samples as this is the region of long bones with both the highest degree of heterogeneity [41, 42, 43] and vascular channel alignment. From each femur two specimens were produced: one with its major axis oriented longitudinally along the long axis of the femur, so that the channels would primarily align with the specimen major axis, and the other with this axis oriented transversely across the radial-circumferential plane so that the vascular channels would predominantly run across the specimen breadth. This produced a total of five specimens for each channel orientation. Each specimen was prepared to an initial length of $20 \mathrm{~mm}$, breadth of $5 \mathrm{~mm}$ and depth of $1.3 \mathrm{~mm}$ using a diamond bladed sectioning saw (Smart Cut 6001, UKAM, USA). This initial sample depth was selected on the basis of previous work [30] which indicated that the reliable identification of size effects required samples of this scale and below. After cutting the samples were meticulously polished with increasingly fine grades (200, 500, 1200 and 2500 grade) of silicon carbide paper and stored in phosphate buffered saline (PBS) solution in a tissue refrigerator at $3^{\circ} \mathrm{C}$ for up to 48 hours.

Samples were loaded in 3-point bending, in a $37^{\circ} \mathrm{C} 0.9 \mathrm{M}$ PBS bath with a $450 \mathrm{~N}$ load cell (BOSE Electroforce 3200, U.S.). The span of the 3-point-bending supports was set to give a 10:1 aspect ratio (length:depth) when loading each specimen. This aspect ratio was deemed sufficiently large enough to satisfy the slender beam assumption implicit in deriving equation 1 while simultaneously avoiding the need to produce excessively slender specimens. Each specimen was ramp loaded to a surface strain of 0.005 at a strain rate of $0.0025 \mathrm{~s}^{-1}$ and held for 10 seconds before being unloaded to zero displacement. The surface strain and strain rate were chosen to preclude the possibility of inducing surface microdamage [44, 45]. Furthermore, after first loading, each sample was then immediately re-orientated to swap the compressive and tensile surfaces in bending and the loading repeated. Each specimen was loaded three times in total. The flexural stiffness of each specimen was derived by applying a linear fit to the loading portion of the measured load displacement relationship. 
The depth of each sample was then reduced from $1.3 \mathrm{~mm}$ to $1.0 \mathrm{~mm}$ then subsequently to 0.7 $\mathrm{mm}$ and finally to $0.5 \mathrm{~mm}$, this being achieved by polishing under PBS solution irrigation using increasingly fine silicon carbide paper (up to 2500 grade) to within $0.05 \mathrm{~mm}$ of the desired dimension. The specimens were then stored in PBS solution at $3{ }^{\circ} \mathrm{C}$ for less than a day prior to testing. Samples were loaded according to the aforementioned procedure after each reduction in depth. The span of the 3-point-bending support jig was adjusted to maintain a constant 10:1 sample aspect ratio at each depth tested.

After testing at each depth, a portion was cut from the end of each sample for surface roughness, volumetric density and mineral content measurement purposes as well as surface imaging. Surface analysis was conducted using an Alicona non-contacting roughness measuring machine to obtain $\mathrm{R}_{\mathrm{a}}$ data. Wet weight and density were determined by measuring samples' volumes and weights with a micrometer and a balance respectively. All specimens were then dried at $100{ }^{\circ} \mathrm{C}$ for 24 hours and then reweighed to give the dry weight and density. Each specimen was finally ashed at $800^{\circ} \mathrm{C}$ for 24 hours and reweighed to determine the ash weight and thereby the mineral and organic contents. Surface images were obtained using an optical microscope

\section{Results}

\subsection{Uniaxial Loading of Idealised Material Virtual Samples}

Effective Young's modulus decreased with increasing void fraction for both the 2D and 3D virtual samples (Table 1). However, for the 2D samples the effective moduli in both loading directions remained similar at any given Vf indicating that the idealised material exhibits approximate planar isotropy across the range of void volume fractions considered. When the void volume fraction is in the region of 0.145 the effective modulus is similar to published values for the radial and circumferential directions in cortical bone [41, 46, 47]. For 3D models, at any given void volume fraction the effective modulus in the sample axial direction, in which the channels are aligned, is greater than both of the moduli in the two orthogonal directions located in the plane of the cross section, these being approximately the same as previously and, moreover, equal to their 2D counterparts. Thus the full three dimensional representation of cortical bone (figure 1) appears to display transverse isotropy. Effective Young's moduli were practically independent of sample size, as forecast by both Cauchy elasticity theory and by more generalized continuum theories.

\subsection{Three Point Bending of Idealised Material Virtual Samples}

For virtual samples with transversely oriented voids and those with axially aligned channels an increase in void volume fraction is accompanied by a reduction in stiffness when top and bottom surfaces are straight and smooth (Figures 4a and 4b). Also, at a given void volume fraction the stiffness of the perforated material increases with reducing sample depth, as predicted by micropolar elasticity theory. Furthermore, the magnitude of size effect, as measured by the gradient of the linear stiffness variation, becomes more marked as the void 
volume fraction is increased. In contrast however, when the material surface morphology is changed due to intersection with the array of voids, stiffness decreases as sample size reduced (Figures $4 \mathrm{c}$ and $4 \mathrm{~d}$ ); behaviour that is not forecast by either Cauchy elasticity or more generalized continuum theories. If these stiffness variations are extrapolated back to the stiffness axis (i.e. $d$ tends to infinity) then the intercept for any given void volume fraction matches that obtained from figures $4 \mathrm{a}$ and $\mathrm{b}$. Interestingly, the gradients of the size effects in the smooth-surface and void-intersected surface cases are very similar in magnitude although of opposite sign (Figure 4e and f). In addition, at the lower aspect ratio of 10.4:1, the samples exhibit a similar linear variation in stiffness with size to the more slender 20:8:1 beams and thus yield, from equation 1, the same characteristic length values at a given Vf (Table 2). Therefore, the fact that the stiffness variation seen at the lower aspect ratio remains linear and also provides consistent characteristic length data implies that the slenderness of the samples is sufficient to concur with the behaviour anticipated of a slender micropolar beam. This vindicates the adoption of the more practicable 10:1 sample aspect ratio in the experimental three-point bend tests.

\subsection{Experimental Three Point Bending}

There was no statistically significant correlation (Pearson's) of mineral content $(p=0.108$ ) or surface roughness $(\mathrm{p}=0.725)$ with sample size, negating potential confounding factors of stiffness [28, 48, 49, 50, 51]. Specimens with axially aligned channels become significantly more compliant as their size is reduced (Figure 5, repeated measures ANOVA, p < 0.001) contradicting predictions of both Cauchy and generalized elasticity theories. However, there is a convincing correspondence between the size effect seen previously for human cortical bone [30] and that seen now for its bovine counterpart providing confidence that the size effect is a genuine feature of the material behaviour (Figure 5). Optical imaging of the specimen surfaces reveals that the channels are partially exposed and aligned along the sample major axis (figure 6). Specimens with transversely oriented voids behave similarly to those that are axially perforated. However, for a given specimen depth, the stiffness of the former is less than that of the latter and, secondly, the size effect, although evident, is less pronounced (figure 7).

\section{Discussion}

Since the size effects of smooth-surfaced FE models (figures $4 a$ and $4 b$ ) show the variation in flexural stiffness with sample size, anticipated by equation 1 , the flexural modulus and characteristic length may be derived from the intercept and gradient respectively for both the two dimensional virtual samples (Table 2) and their three dimensional equivalents (Table 3). For each void volume fraction considered in table 2 , the derived values of the flexural modulus agree with the moduli quoted in table 1 for uniform uniaxial loading. Thus the assumptions regarding the flexural mode of deformation, implicit in equation 1 and hence in obtaining these data are apparently valid. However, the flexural modulus values for the three dimensional material are not the same as those of its two dimensional counterpart, 
highlighting the genuinely anisotropic nature of the material illustrated in figure 1 and thus its suitability as an idealised representation of cortical bone.

The flexural modulus and characteristic length data given in tables 2 and 3 are relatively insensitive to the sample aspect ratio thus further vindicating the decision to perform the experimental flexural tests on cortical bone samples with an aspect ratio of only 10:1. Characteristic length values increase linearly with void diameter, confirming recent theoretical forecasts [52]; the constants of proportionality being 1.4 for the 2D material and 0.8 for the $3 \mathrm{D}$ material, emphasizing the anisotropy displayed by the representative material.

When the surface was intersected with voids, stiffness decreased with decreasing size, behaviour predicted by neither Cauchy elasticity nor generalized continuum theories. Nevertheless, it has recently been demonstrated that a simple heterogeneous material comprised of alternating stiff and compliant laminae can exhibit size effects that are consistent with those forecast by generalized elasticity theories [31]. The behaviour of the simple laminated material is consistent with that of a Cosserat-type material when the surface layers are comprised of the stiffer of the two constituents but when the more compliant material forms the surfaces the material exhibits decreasing stiffness with reducing beam depth. Thus we may infer that such anti-Cosserat behaviour, namely decreasing stiffness with reducing beam depth, is associated with a reduced stiffness of the surface layers. The partial exposure of the vascular channel system, clearly evident in a magnified image of a typical test specimen surface (Figure 6), and the associated increase in compliance of the adjacent material over that of the bulk may be considered to be the primary source of the negative size effect identified in bovine cortical bone.

Figures $4 \mathrm{e}$ and $4 \mathrm{f}$ propose that, for any given void volume fraction, the gradients of the two possible size effects for smooth and non-smooth surfaces are essentially the negative of each other. Whilst this observation is empirical in nature and, to date, without theoretical support, it does offer a pragmatic solution to the problem of determining the constitutive properties of materials that exhibit the kinds of size effects seen in figures $4 \mathrm{c}, 4 \mathrm{~d}$ and indeed Figure 5. Utilising this argument, both modulus and characteristic length data may be derived for bovine cortical bone from the observed size effects (Table 4).

While the qualitative similarity between the numerically forecast and experimentally observed size effects is evident, the former were predicated on generating the finite element representations of the idealised material using a presumed unit cell spacing of $1 \mathrm{~mm}$. To facilitate more direct quantitative comparison between the numerical and experimental results it was necessary to rescale the cell spacing used in generating the finite element meshes. Thus $\mathrm{S}_{\mathrm{X}}$ was reset to $500 \mu \mathrm{m}$ with $\mathrm{S}_{\mathrm{Y}}$ being scaled accordingly. This value was selected on the basis that it not only reflects the upper bound of channel separation typically observed in bovine cortical bone but would also enable the generation of finite element models with dimensions, notably the virtual sample depth, that, while not identical to those of the experimentally tested specimens, were very similar. Since in the experimental test specimens the vascular channel system is clearly exposed (figure 6) only those models where the 
channels were intersecting the sample surfaces, in the manner of figures $2 \mathrm{~d}$ and $3 \mathrm{~d}$, were regenerated but now at void volume fractions ranging from of 0.009 through $0.036,0.082$, $0.145,0.227$ to 0.326 . The Young's modulus of the material matrix within the models was however retained at $20 \mathrm{GPa}$ as previously. The best match between numerical and experimental results was established by firstly determining the difference, in a least squares sense, between the measured stiffness variation and that forecast at each of the chosen void volume fractions and then identifying the minimum difference. Independent comparisons of results were made for the axially and transversely aligned void cases.

Intriguingly, the best match (Figure 7) occurred at the same volume fraction in both the transversely and axially aligned cases and, moreover, it is encouraging to note that the void volume fraction of $14.5 \%$ that provides this match is on the upper end of the range of typically observed values of porosity in cortical bone (5-15\%) [36, 37, 38, 39, 40]. Defining the totality of material anisotropy as being expressed by the vascular channel network is an assumption in the numerical simulations that does not account for matrix material anisotropy as has been observed in cortical bone [53, 54]. It is nevertheless worth noting that the simplifications in the numerical model are intended to be a generalisation of the entire material anisotropy. Furthermore, the consequences of assuming matrix material isotropy may contribute to the high porosity observed when fitting experimental and numerical results because larger vascular channels will be required in order to accommodate for all of the material anisotropy. Additionally, the experimentally observed Young's modulus values (Table 4) indicate that the recorded modulus is lower than those observed in previous bovine experiments $(20 \mathrm{GPa})$ which may be indicative of a higher porosity in the experimental specimens. It is particularly interesting to note that the characteristic length values (Table 4) are of similar dimensions to the sizes reported for vascular channels and Haversian canals in primary and secondary osteons respectively $[55,56,57]$. However, these characteristic length values are somewhat tentative since they are derived by equating the computed or observed negative size effects to their positive equivalents (figures $4 \mathrm{e}$ and $4 \mathrm{f}$ ) to enable their calculation using equation 1 . Nevertheless, it is reassuring to note that despite the simplicity of the representative material, both the modulus and characteristic length data derived computationally reflect the experimentally determined values (Table 4), endorsing the material as a valid representation for identifying the global mechanical behaviour of cortical bone which, as the experimental results clearly identify, is evidently non classical. A better match may be realised by optimising the values for Young's modulus and void fraction simultaneously.

The work presented here indicates that in circumstances where the microstructural length scale becomes significantly large relative to the surrounding geometrical features then the assumption of Cauchy elasticity will no longer provide an accurate prediction of stress locally within the material. This is of particular importance when considering the bone-implant interface where localised stresses may result in loosening and improper osseointegration. The idealised nature of the numerical model used in this study has been based upon several assumptions, principally: that the matrix material is isotropic and the global material anisotropy is generated solely from the vascular channel network; and that the vascular 
channels are aligned longitudinally along the long axis of cortical bone. Including a degree of anisotropy into the matrix material would lend more microstructural detail of smaller length scales to the model whilst allowing a more accurate comparison between the experimentally observed characteristic lengths and the vascular channels. Similarly, the alignment of vascular channels and Haversian canals is known to be more isotropic at the epiphysis regions of long bones, therefore the greatest degree of anisotropy and thus similarity between the numerical model and cortical bone behaviour will be observed at primarily the diaphyseal regions of long bones.

\section{Conclusions}

Finite element modelling of a virtual material comprised of a regular array of tubular voids in an otherwise classically elastic matrix has exhibited size dependent behaviour that is consistent with that of generalized continua of the Cosserat type and with that observed in experimental tests on cortical bone samples. The nature of the size effect is intimately related to the character of the material sample surfaces. Furthermore, it is extremely encouraging to note that the finite element models are capable of quantitatively reproducing the experimentally observed behaviour when the key input parameters, namely the void spacing, the void volume fraction and the matrix modulus, reflect those typically encountered in cortical bone. Finally, the characteristic length data, for which there is little to compare against in the existing literature, appear to reflect the length scales associated with the major microstructural feature present in cortical bone: the vascular channel.

\section{Acknowledgements}

While undertaking this work Jamie Frame was supported by a PhD studentship funded by the Engineering and Physical Sciences Research Council (EPSRC) through the Doctoral Training Centre in Medical Devices based at the Department of Biomedical Engineering, University of Strathclyde.

\section{References}

[1] Huiskes, R. \& Hollister, S.J. (1993). From structure to process, from organ to cell::recent developments of FE-analysis, orthopaedic biomechanics. ASME Journal of Biomedical Engineering 115 (4B), 520-527

[2] Prendergast, P.J. \& Taylor D. (1990). Stress analysis of the proximo-medial total hip replacement. Journal of biomedical engineering. 12, 379-382

[3] Sathappan, S.S., Pang, H., Alikkal, M., Thambayah, A. \& Satku, K. (2009). Does stress shielding occur with the use of long-stem prosthesis in total knee arthroplasty? Knee surgery, sports traumology, arthroscopy: official journal of ESSKA. 17 (2), 179-183 
[4] McNamara, B.P., Cristofini, L., Toni, A. \& Taylor, D. (1997). Relationship between bone-prosthesis bonding and load transfer in total hip reconstruction. Journal of Biomechanics. 30 (6), 621-630

[5] Patel R. J., Wright T. M., \& Gao Y., (2014). Load transfer after cemented total shoulder arthroplasty. Journal of Shoulder and Elbow Surgery, 23(10), 1553-1562.

[6] Enoksen C. H., Gjerdet N. R., Klaksvik J., Arthursson A. J., Schnell-Husby O., \& Wik T. S., (2016). Deformation pattern and load transfer of an uncemented femoral stem with modular necks. An experimental study in human cadaver femurs. Clinical Biomechanics, 32, $28-33$.

[7] Lee J. I., Lee Y., Kim Y. L., \& Cho H. W., (2016). Effect of implant number and distribution on load transfer in implant-supported partial fixed dental prostheses for the anterior maxilla: A photoelastic stress analysis study. Journal of Prosthetic Dentistry, 115(2), $161-169$.

[8] Bauer, T.W. \& Schils J. (1999). The pathology of total joint arthroplasty II. Mechanisms of implant failure. Skeletal radiology 28, 483-497

[9] Huang C. C., Jiang C. C., Hsieh C. H., Tsai C. J., \& Chiang H., (2016). Local bone quality affects the outcome of prosthetic total knee arthroplasty. Journal of orthopedic Research, 34(2), 240-248.

[10] Howashi M., Tsukiyama, Y., Ayukawa, Y., Isoda-Akizuki, K., Kihara, M., Imai, Y., Sogo, M. \& Koyano, K., (2016). Relationship between the CT Value and Cortical Bone Thickness at Implant Recipient Sites and Primary Implant Stability with Comparison of Different Implant Types. Clinical Implant Dentistry and Related Research, 18(1), 107-116.

[11] Hogan, H.A., (1992). Micromechanics modeling of Haversian cortical bone properties. Journal of Biomechanics, 5, 549-556.

[12] Braidotti, P., Branca, F.P., Sciubba, E., \& Stagn, L., (1995). An elastic compound tube model for a single osteon. Journal of biomechanics, 28(4), 439-444.

[13] Kouznetsova, V., Geers, M.G.D. \& Brekelmans, W. a. M., (2002). Multi-scale constitutive modelling of heterogeneous materials with a gradient-enhanced computational homogenization scheme. International Journal for Numerical Methods in Engineering, 54(8), $1235-1260$.

[14] Ghoniem, N., Busso, E.P., Kioussis, N. \& Huang, H. (2003). Multiscale modelling of nanomechanics and micromechanics: an overview. Philosophical Magazine, 83(31), 34753528.

[15] Ladevèze, P., (2004). Multiscale modelling and computational strategies for composites. International Journal for Numerical Methods in Engineering, 60(1), 233-253. 
[16] Ghanbari, J. \& Naghdabadi, R., (2009). Nonlinear hierarchical multiscale modeling of cortical bone considering its nanoscale microstructure. Journal of biomechanics, 42(10), $1560-5$.

[17] Bala, Y., Depalle, B., Douillard, T., Meille, S., Clément, P., Follet, H., Chevalier, J. \& Boivin, G. (2011). Respective roles of organic and mineral components of human cortical bone matrix in micromechanical behavior: an instrumented indentation study. Journal of the mechanical behaviour of biomedical materials, 4(7), 1473-82

[18] Eringen, A.C., (1966). Linear theory of micropolar elasticity. Journal of Mathematics and Mechanics, 15(6):909-923

[19] Eringen, A.C., (1999). Microcontinuum Field Theories I: Foundations and Solids. Springer-Verlag New York

[20] Askar, A. \& Cakmak A.S. (1968), A structural model of a micropolar continuum, International Journal of Engineering Science, 6, 583-589

[21] Banks, C.B. \& Sokolowski, M. (1968), On certain two-dimensional applications of the couple stress theory. International Journal of Solids and Structures, 4, 15-29

[22] Bažant, Z.P. \& Christensen, M. (1972), Analogy between micropolar continuum and grid frameworks under initial stress, International Journal of Solids and Structures, 8, 327346

[23] Beveridge, A.J., Wheel, M.A. \& Nash, D.H. (2013), The Micropolar Elastic Behaviour of Model Macroscopically Heterogeneous Materials, International Journal of Solids \& Structures, 50, 246-255

[24] Waseem, A., Beveridge, A.J., Wheel, M.A. \& Nash, D. (2013), The influence of void size on the micropolar constitutive properties of model heterogeneous materials, European Journal of Mechanics A: Solids. 40, 148-157

[25] McGregor, M. \& Wheel, M.A. (2014), On the coupling number and characteristic length of micropolar media of differing topology, Proceedings of the Royal Society A, 470(2169): 20140150

[26] Lakes, R.S. (1983), Size effects and micromechanics of a porous solid. Journal of Materials Science, 18, 2572-2580

[27] Lakes, R.S. (1986), Experimental microelasticity of two porous solids. International Journal of Solids and Structures, 22, 55-63 
[28] Anderson, W.B. \& Lakes, R.S., (1994), Size effects due to Cosserat elasticity and surface damage in closed-cell polymethacrylimide foam, Journal of Materials Science, 29, 6413-6419

[29] Yang, J.F.C. \& Lakes, R.S. (1982), Experimental study of micropolar and couple stress elasticity in bone in bending. Journal of Biomechanics, 15, 91-98

[30] Choi, K., Kuhn, J.L., Ciarelli, M.J. \& Goldstein, S.A. (1990). The elastic moduli of human subchondral, trabecular, and cortical bone tissue and the size-dependency of cortical bone modulus. Journal of Biomechanics, 23(11), 1103-1113.

[31] Wheel, M.A., Frame, J.C. \& Riches, P.E. (2015), Is Smaller Always Stiffer? On Size Effects In Supposedly Generalized Continua, International Journal of Solids and Structures $(67-68), 84-92$

[32] Qwamizadeh, M., Zhang, Z., Zhou, K. \& Zhang, Y.W. (2015). On the relationship between the dynamic behavior and nanoscale staggered structure of the bone, Journal of Mechanics and Physics of Solids, 78, 17-31.

[33] Zhang, Z., Zhang Y.W. \& Gao, H. (2011). On optimal hierarchy of load-bearing biological materials, Proceedings of the Royal Society B: Biological Sciences, 278, 519-525

[34] Evans, G.P., Behiri, J.C., Currey, J.D. \& Bonfield, W. (1990). Microhardness and Young's modulus in cortical bone exhibiting a wide range of mineral volume fractions, and in a bone analogue. Journal of Materials Science: Materials in Medicine, 1(1), 38-43.

[35] Rho, J.Y, Ashman, R.B. \& Turner, C.H. (1993). Young's modulus of trabecular and cortical bone material: Ultrasonic and microtensile measurements. Journal of Biomechanics, 26(2), 111-119.

[36] Rho, J.Y., Kuhn-Spearing, L. \& Zioupos, P. (1998). Mechanical properties and hierarchical structure of bone. Medical Engineering and Physics. 20, 92-102

[37] M., Malo, Rohrbach, D., Isaksson, H., Töyräs, J., Jurvelin, J. S., Tamminen, I. S., Kröger, H. \& Raum, K. (2013). Longitudinal elastic properties and porosity of cortical bone tissue vary with age in human proximal femur. Bone, 53(2), 451-458.

[38] Thomas C. D. L., Feik S. A. \& Clement J. G. (2005). Regional variation of intracortical porosity in the midshaft of the human femur: Age and sex differences. Journal of Anatomy, 206(2), 115-125.

[39] Bousson, V., Meunier, A., Bergot, C., Vicaut, E., Rocha, M. A., Morais, M. H., LavalJeantet, A. M. \& Laredo, J. D., (2001). Distribution of intracortical porosity in human midfemoral cortex by age and gender. Journal of Bone and Mineral Research, 16(7), 13081317. 
[40] Bell K. L., Loveridge N., Power J., Garrahan N., Meggitt B. F. \& Reeve J (1999). Regional differences in cortical porosity in the fractured femoral neck. Bone, 24(1), 57-64

[41] Pope, M.H. \& Outwater, J.O. (1974). Mechanical properties of bone as a function of position and orientation. Journal of Biomechanics, 7, 61-66

[42] Katz, J.L. \& Yoon, H.S., (1984). The structure and anisotropic mechanical properties of bone. IEEE transactions on bio-medical engineering, 31(12), 878-84

[43] Macione, J., DePaula, C.A., Guzelsu, N. \& Kotha, S.P. (2010). Correlation between longitudinal, circumferential, and radial moduli in cortical bone: effect of mineral content. Journal of the mechanical behaviour of biomedical materials, 3(5), 405-13

[44] Zioupos, P. \& Currey, J.D. (1994). The extent of microcracking and the morphology of microcracks in damaged bone. Journal of Materials Science, 29, 978-986.

[45] Zioupos, P, Hansen, U. \& Currey, J.D. (2008). Microcracking damage and the fracture process in relation to strain rate in human cortical bone tensile failure. Journal of Biomechanics, 41(14), 2932-9.

[46] Turner, C.H., Chandran, A., \& Pidaparti, R.M. (1995). The anisotropy of osteonal bone and its ultrastructural implications. Bone, 17(1), 85-9.

[47] Akiva, U., Wagner, H. \& Weiner, S., (1998). Modelling the three-dimensional elastic constants of parallel-fibred and lamellar bone. Journal of materials science, 33(6), 14971509 .

[48] Currey, J.D. (1969). The mechanical consequences of variation in the mineral content of bone, Journal of Biomechanics 2(1), 1-11.

[49] Currey, J.D. (1975). The effects of strain rate, reconstruction and mineral content on some mechanical properties of bovine bone. Journal of Biomechanics, 8, pp.81-86.

[50] Currey, J.D. (1988). The effect of porosity and mineral content on the Young's modulus of elasticity of compact bone. Journal of Biomechanics, 21(2), pp.131-139.

[51] Burnstein, A.H., Zika, J.M., Heiple, K.G. \& Lein, L. (1975). Contribution of collagen and mineral to the elastic-plastic properties of bone. Journal of Bone and Joint Surgery, 57(7), 956-961.

[52] Bigoni, D. \& Drugan, W.J. (2007), Analytical derivation of Cosserat moduli via homogenization of heterogeneous elastic materials, Journal of Applied Mechanics, 74, 741753 
[53] Hamed E., Lee Y., \& Jasiuk I., (2010). Multiscale modeling of elastic properties of cortical bone. Acta Mechanica, 213(1-2), 131-154.

[54] Grimal, Q., Rus, G., Parnell, W. J., \& Laugier P., (2011). A two-parameter model of the effective elastic tensor for cortical bone. Journal of Biomechanics., 44(8), 1621-1625.

[55] Black, J., Mattson, R. \& Korostoff, E., (1974). Haversian osteons: size, distribution, internal structure, and orientation. Journal of biomedical materials research, 8(5), 299-319.

[56] Smit, T.H., Huyghe, J.M. \& Cowin, S.C., (2002). Estimation of the poroelastic parameters of cortical bone. Journal of Biomechanics, 35(6), 829-835

[57] Zhang, J., Niebur, G.L. \& Ovaert, T.C., (2008). Mechanical property determination of bone through nano- and micro-indentation testing and finite element simulation. Journal of Biomechanics, 41(2), 267-75

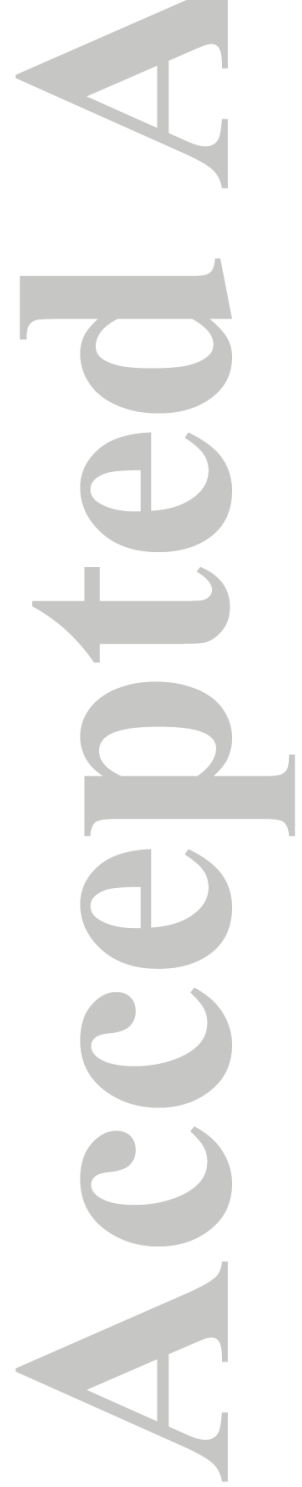




\begin{tabular}{|c|c|c|c|c|c|c|c|c|c|}
\hline & \multicolumn{9}{|c|}{ Void Volume Fraction, $V_{F}$} \\
\hline & \multicolumn{3}{|c|}{0.036} & \multicolumn{3}{c|}{0.145} & \multicolumn{3}{c|}{0.326} \\
\hline & $\begin{array}{c}\mathrm{EX} \\
(\mathrm{GPa})\end{array}$ & $\begin{array}{c}\mathrm{EY} \\
(\mathrm{GPa})\end{array}$ & $\begin{array}{c}\mathrm{Ez} \\
(\mathrm{GPa})\end{array}$ & $\begin{array}{c}\mathrm{E}_{X} \\
(\mathrm{GPa})\end{array}$ & $\begin{array}{c}\mathrm{E}_{Y} \\
(\mathrm{GPa})\end{array}$ & $\begin{array}{c}\mathrm{Ez} \\
(\mathrm{GPa})\end{array}$ & $\begin{array}{c}\mathrm{E}_{X} \\
(\mathrm{GPa})\end{array}$ & $\begin{array}{c}\mathrm{E}_{Y} \\
(\mathrm{GPa})\end{array}$ & $\begin{array}{c}\mathrm{Ez} \\
(\mathrm{GPa})\end{array}$ \\
\hline 2D & 17.94 & 17.94 & - & 13.20 & 13.11 & - & 7.94 & 7.63 & - \\
\hline 3D & 17.94 & 17.94 & 19.3 & 13.20 & 13.11 & 17.1 & 7.94 & 7.63 & 13.5 \\
\hline
\end{tabular}

Table 1 Young's moduli for different void volume fractions for the 2D and 3D material specifications 


\begin{tabular}{|c|c|c|c|c|c|c|}
\hline \multirow{2}{*}{$\begin{array}{c}\text { Void } \\
\text { Diameter, } \\
\mathrm{V}_{\mathrm{d}}(\mathrm{mm})\end{array}$} & \multirow{2}{*}{$\begin{array}{c}\text { Void } \\
\text { Fraction } \\
\text { Vf }\end{array}$} & \multirow{2}{*}{$\begin{array}{c}\text { Normalised } \\
\text { void radius } \\
\mathrm{V}_{\mathrm{R}} / \mathrm{S}_{\mathrm{Y}}\end{array}$} & \multicolumn{2}{|c|}{$\begin{array}{l}\text { Flexural Modulus } \\
\qquad(\mathrm{GPa})\end{array}$} & \multicolumn{2}{|c|}{$\begin{array}{c}\text { Characteristic length, } l_{c} \\
(\mathrm{~mm})\end{array}$} \\
\hline & & & $\begin{array}{c}10.4: 1 \\
\text { aspect } \\
\text { ratio }\end{array}$ & $\begin{array}{c}20.8: 1 \\
\text { aspect } \\
\text { ratio }\end{array}$ & $\begin{array}{c}10.4: 1 \\
\text { aspect ratio }\end{array}$ & $\begin{array}{c}20.8: 1 \\
\text { aspect ratio }\end{array}$ \\
\hline 0.2 & 0.036 & 0.16 & 17.47 & 17.87 & 0.28 & 0.28 \\
\hline 0.3 & 0.082 & 0.23 & 15.37 & 15.71 & 0.42 & 0.43 \\
\hline 0.4 & 0.145 & 0.31 & 12.90 & 13.16 & 0.55 & 0.57 \\
\hline 0.5 & 0.227 & 0.39 & 10.31 & 10.50 & 0.66 & 0.70 \\
\hline 0.6 & 0.326 & 0.46 & 7.74 & 7.83 & 0.75 & 0.82 \\
\hline
\end{tabular}

Table 2 Comparison of the flexural moduli and characteristic lengths for different void radii at 10.4:1 and 20.8:1 length to depth aspect ratios for the two dimensional material with $\mathrm{S}_{\mathrm{X}}$ of $1.0 \mathrm{~mm}, \mathrm{~S}_{\mathrm{Y}}$ of $0.866 \mathrm{~mm}$, and matrix modulus of $20 \mathrm{GPa}$. 


\begin{tabular}{|c|c|c|c|c|c|c|}
\hline \multirow{2}{*}{$\begin{array}{c}\text { Void } \\
\text { Diameter, } \\
\mathrm{V}_{\mathrm{d}}(\mathrm{mm})\end{array}$} & \multirow{2}{*}{$\begin{array}{c}\text { Void } \\
\text { Fraction } \\
\text { Vf }\end{array}$} & \multirow{2}{*}{$\begin{array}{c}\text { Normalised } \\
\text { void radius } \\
\mathrm{V}_{\mathrm{R}} / \mathrm{S}_{\mathrm{Y}}\end{array}$} & \multicolumn{2}{|c|}{$\begin{array}{l}\text { Flexural Modulus } \\
\qquad(\mathrm{GPa})\end{array}$} & \multicolumn{2}{|c|}{$\begin{array}{l}\text { Characteristic length, } l_{c} \\
(\mathrm{~mm})\end{array}$} \\
\hline & & & $\begin{array}{c}10: 1 \\
\text { aspect } \\
\text { ratio }\end{array}$ & $\begin{array}{c}20: 1 \\
\text { aspect } \\
\text { ratio }\end{array}$ & $\begin{array}{l}\text { 10:1 aspect } \\
\text { ratio }\end{array}$ & $\begin{array}{l}\text { 20:1 aspect } \\
\quad \text { ratio }\end{array}$ \\
\hline 0.1 & 0.009 & 0.07 & 19.1 & 19.7 & 0.07 & 0.08 \\
\hline 0.2 & 0.036 & 0.16 & 18.6 & 19.1 & 0.16 & 0.16 \\
\hline 0.3 & 0.082 & 0.23 & 17.7 & 18.2 & 0.23 & 0.24 \\
\hline 0.4 & 0.145 & 0.31 & 16.4 & 17.0 & 0.31 & 0.32 \\
\hline 0.5 & 0.227 & 0.39 & 14.8 & 15.3 & 0.39 & 0.40 \\
\hline 0.6 & 0.326 & 0.46 & 12.8 & 13.3 & 0.46 & 0.48 \\
\hline
\end{tabular}

Table 3 Comparison of the flexural moduli and characteristic lengths for different void radii at 10:1 and 20:1 length to depth aspect ratios for the three dimensional material with $S_{X}$ of $1.0 \mathrm{~mm}, \mathrm{~S}_{\mathrm{Y}}$ of $0.866 \mathrm{~mm}$, and matrix modulus of $20 \mathrm{GPa}$. 


\begin{tabular}{|c|c|c|c|c|}
\hline & $E_{m}$ axial & $l_{b}$ axial & $E_{m}$ transverse & $l_{b}$ transverse \\
\hline Experimental & $17.9 \mathrm{GPa}$ & $57 \mu \mathrm{m}$ & $8.6 \mathrm{GPa}$ & $44 \mu \mathrm{m}$ \\
$\mathrm{FE}$ & $16.4 \mathrm{GPa}$ & $35 \mu \mathrm{m}$ & $8.4 \mathrm{GPa}$ & $58 \mu \mathrm{m}$ \\
\hline
\end{tabular}

Table 4 A comparison between the values of flexural modulus and characteristic length in bending, $l_{b}$, for the specimens with axial and transversely orientated voids derived from experimentally measured size effects and those computed with a void fraction of $0.145, \mathrm{~S}_{\mathrm{X}}$ of $0.5 \mathrm{~mm}, \mathrm{~S}_{Y}$ of $0.433 \mathrm{~mm}$, and matrix modulus of $20 \mathrm{GPa}$. 


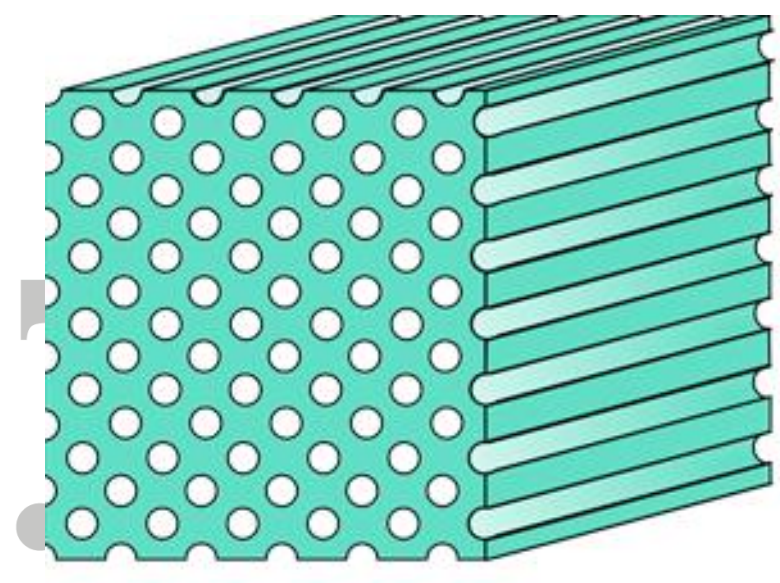

(a)

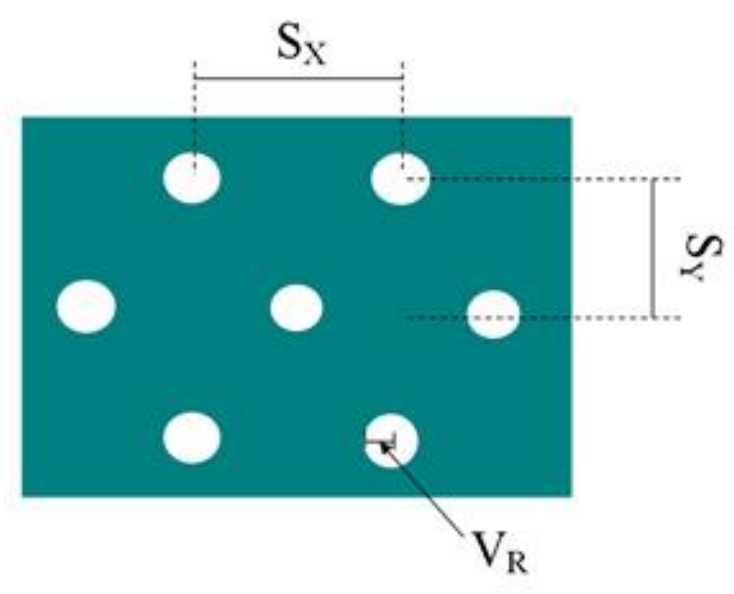

(b)

Figure 1 - (a) Idealized representation of cortical bone with (b) geometric parameters indicated. 


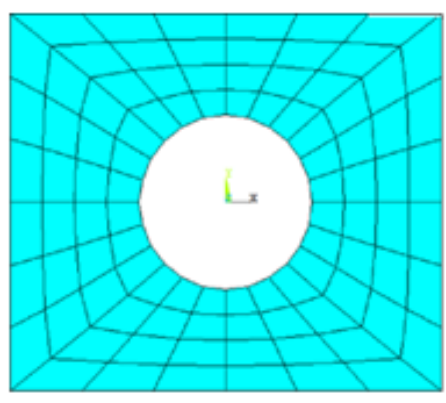

(a)

\section{Q000}

000000000

(c)

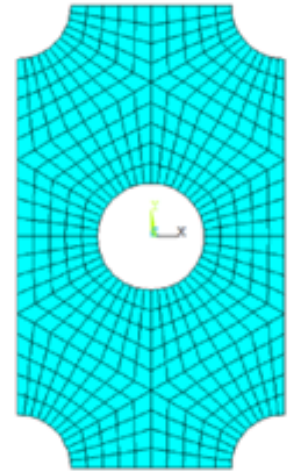

(b)

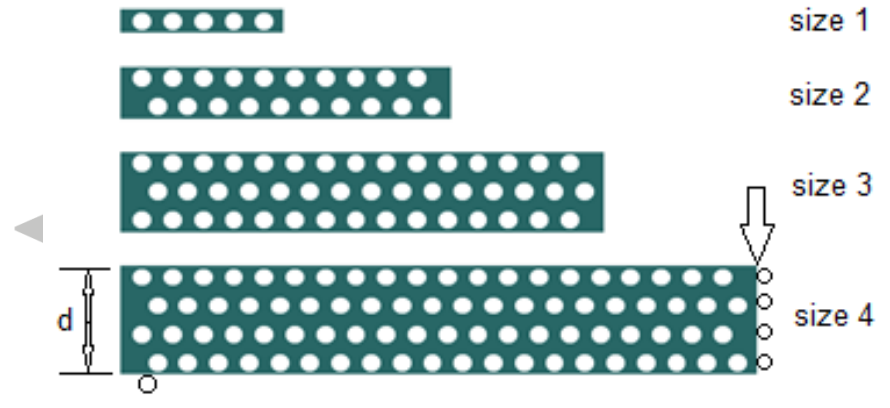

Figure $2(a, b)$ Structured meshes of planar quadrilateral elements used to represent region around particular void in the idealized material with (c) smooth surfaces and (d) surface with voids 


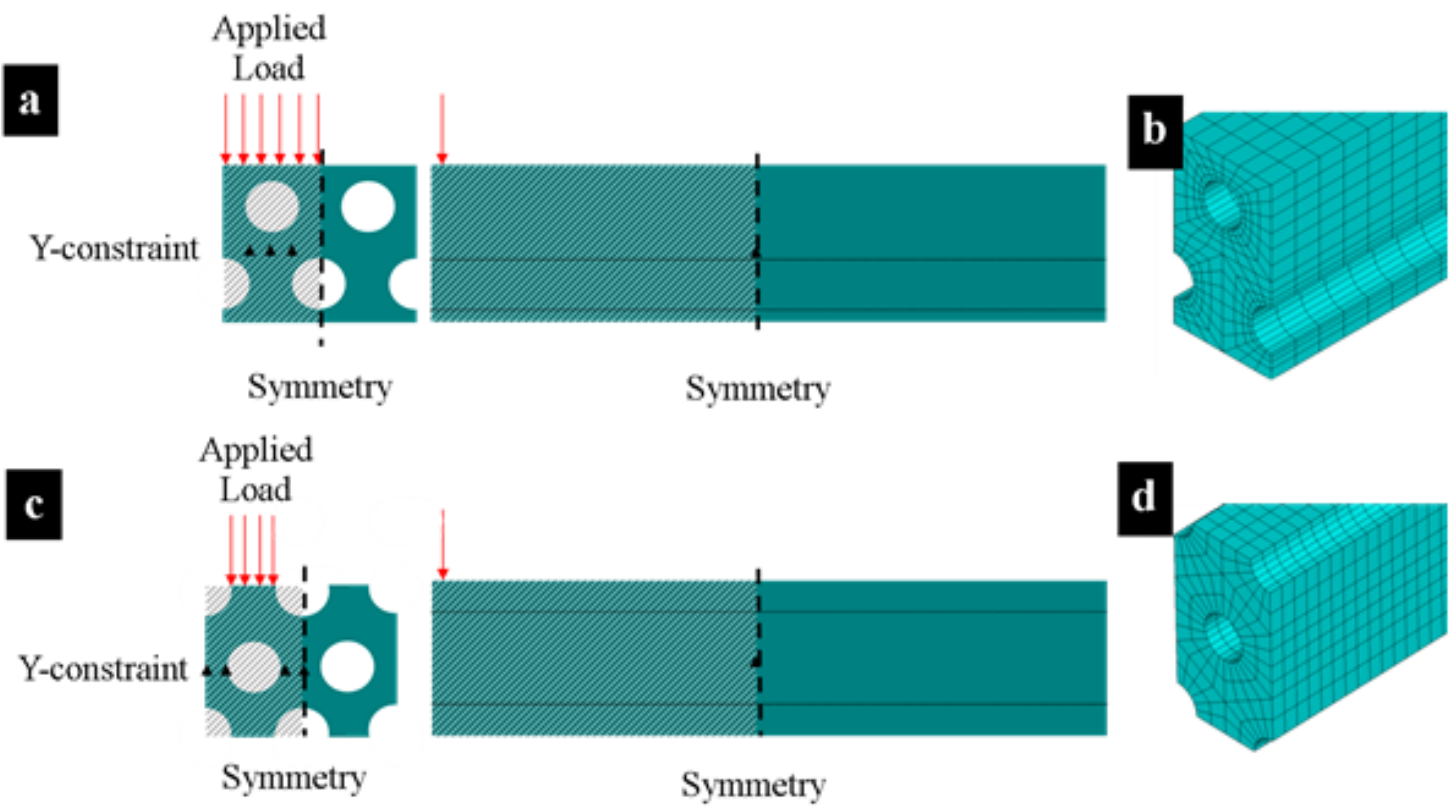

Figure 3 Beam samples with axially aligned voids represented by three dimensional finite element meshes.

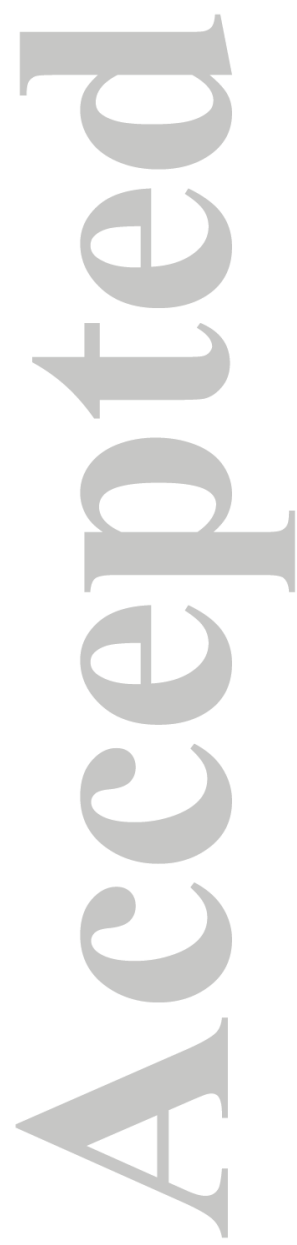



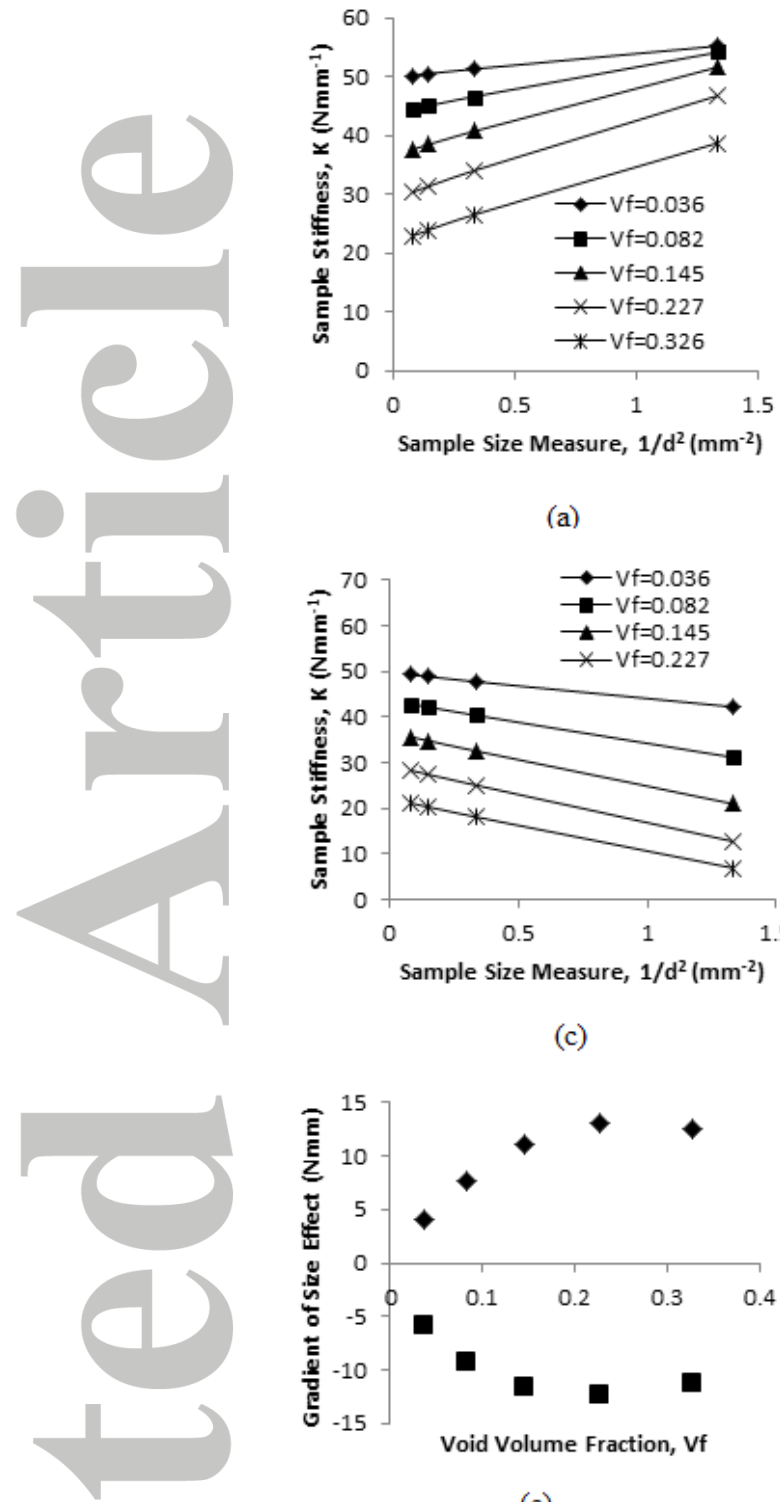

(a)

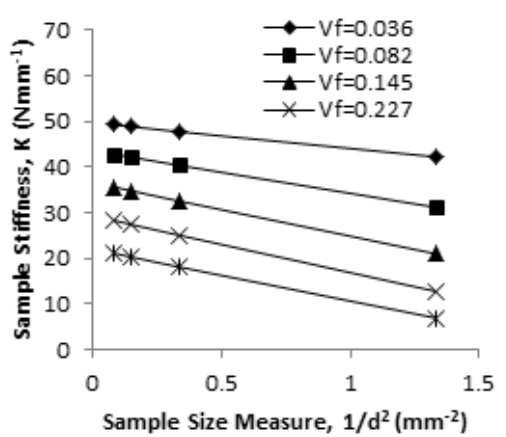

(c)

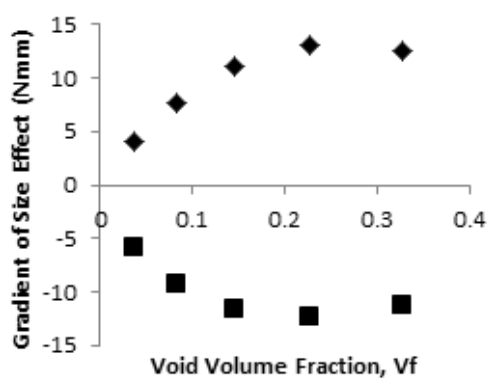

(e)

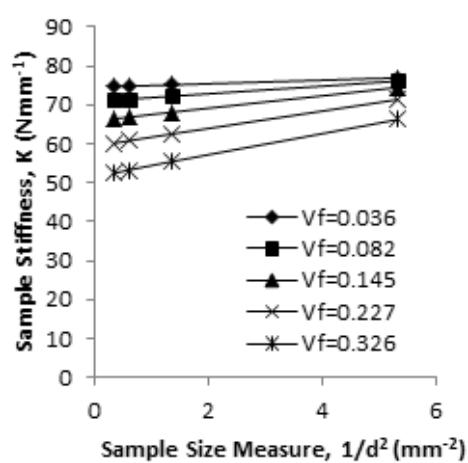

(b)

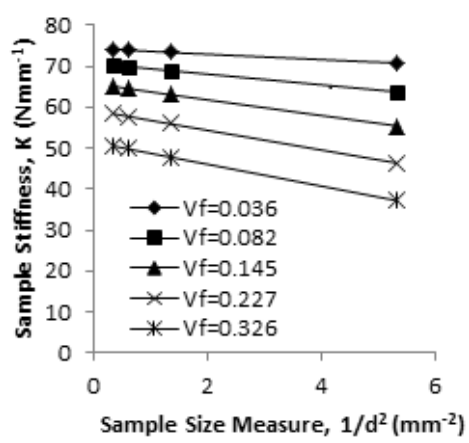

(d)

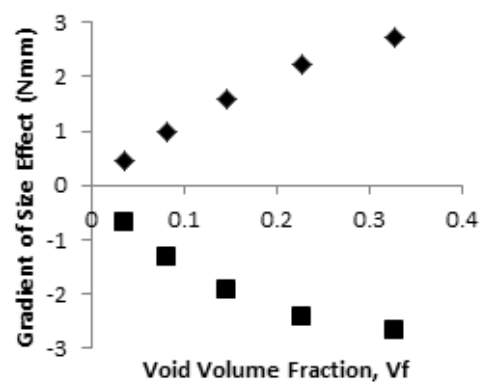

(f)

Figure 4 Variation in flexural stiffness with sample size measure, $\left(1 / d^{2}\right)$, for $(a, b)$ smooth surfaced beams with length to depth aspect ratio of 10.4:1; (c, d) perforated surface beams with a length to depth aspect ratio of $10.4: 1 ;(\mathrm{e}, \mathrm{f})$ variation in the gradient of the size effect in smooth and perforated surface samples.

Transversely aligned voids (a, c, e); axially aligned channels (b, d, f) 


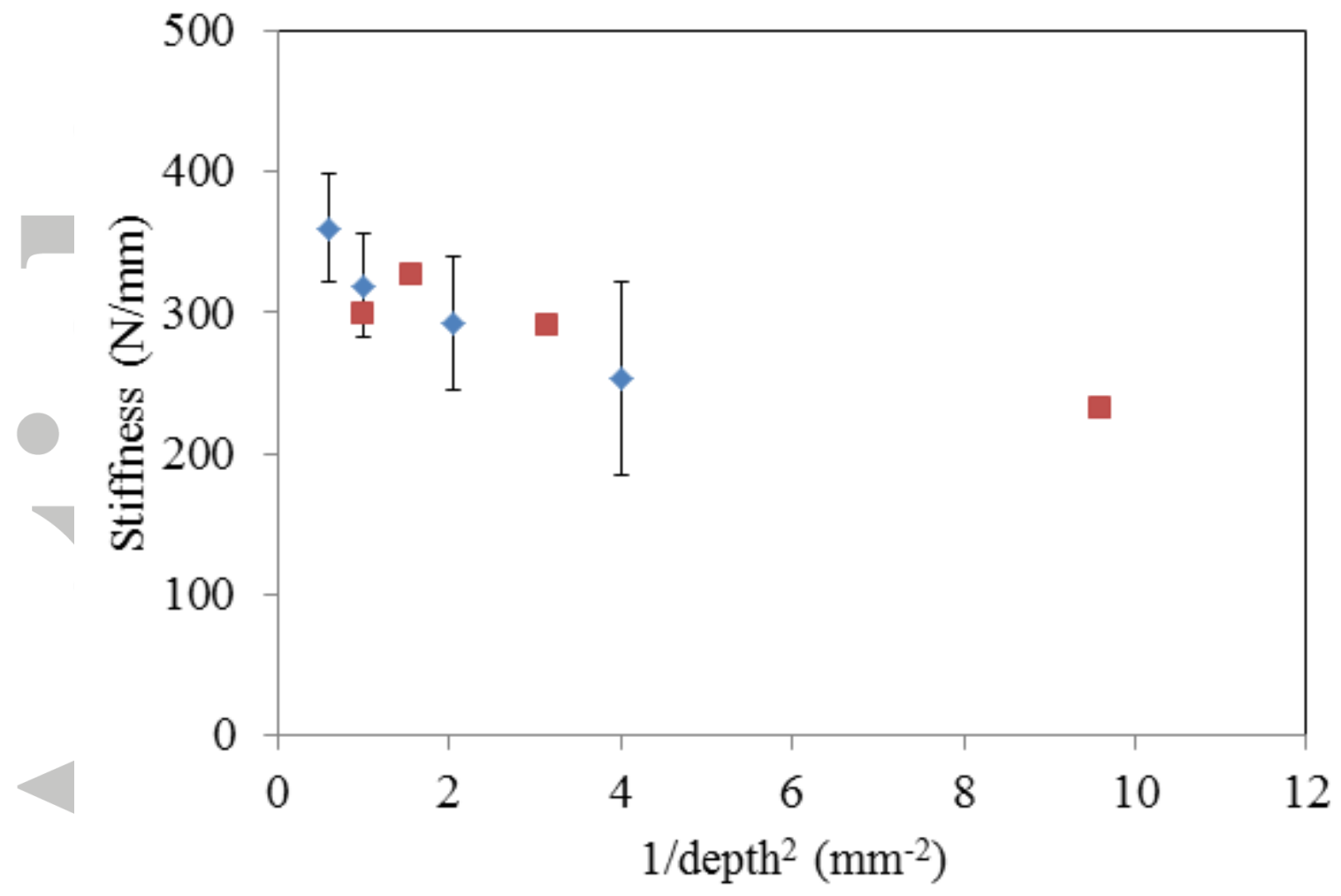

Figure 5 Comparison of size effect seen in bovine cortical bone samples (diamonds) with that seen previously in human cortical bone samples (squares) [30]. 

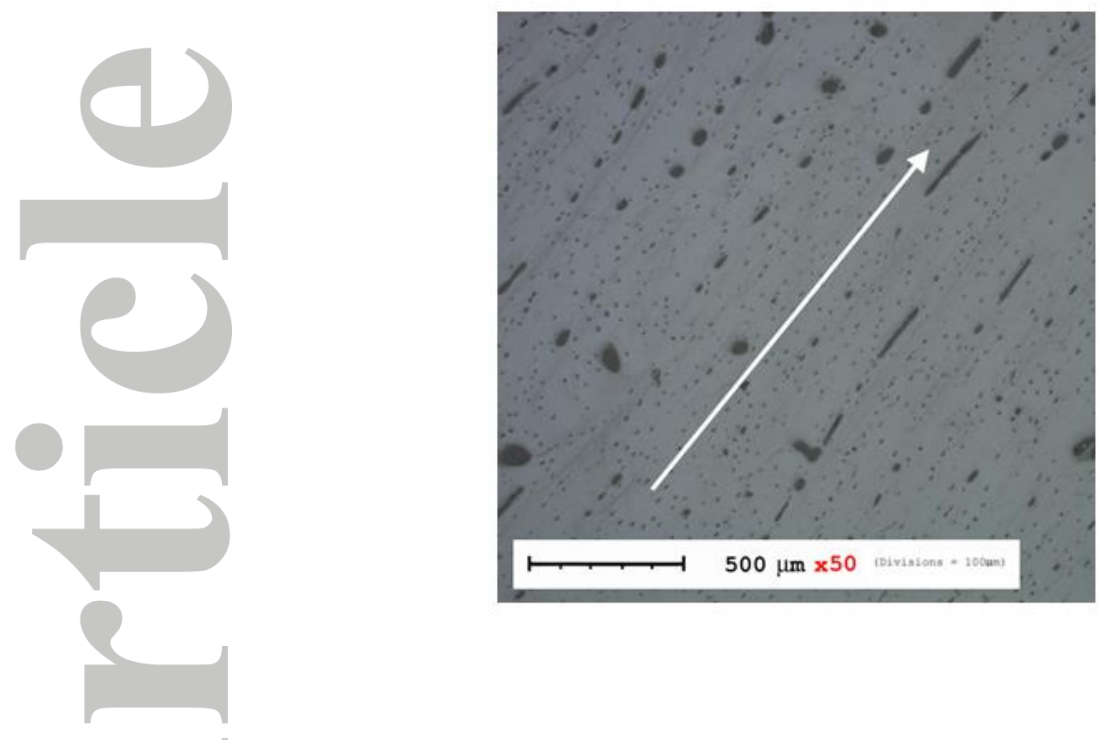

Figure 6-Surface image of typical flexural test specimen. Partially exposed vascular channels associated with primary and secondary osteons can be seen to be aligned along the major axis of the specimen (white arrow). 

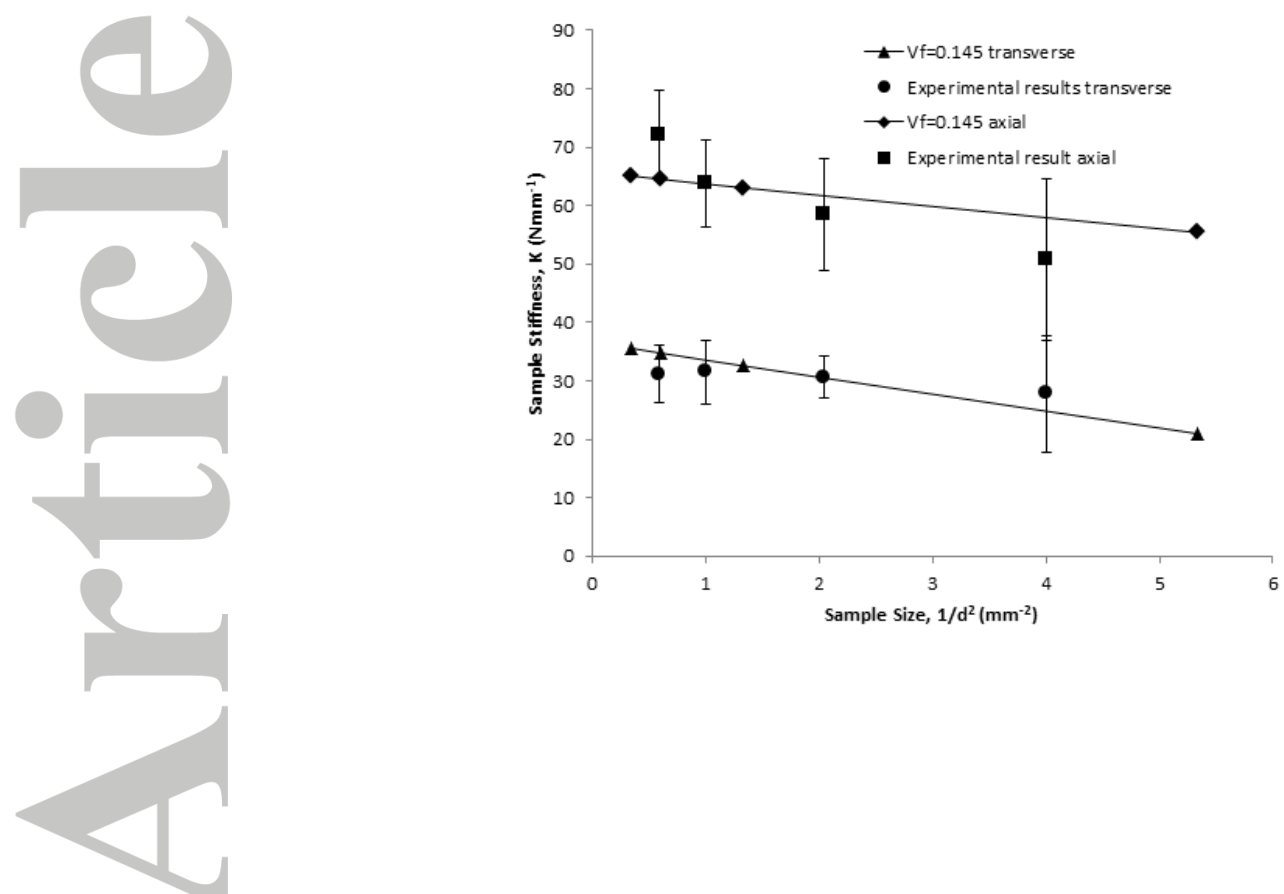

Figure 7 Comparison of the experimental determined stiffness variation with the FE results obtained at a void volume fraction of 0.145 for both channel orientation cases.

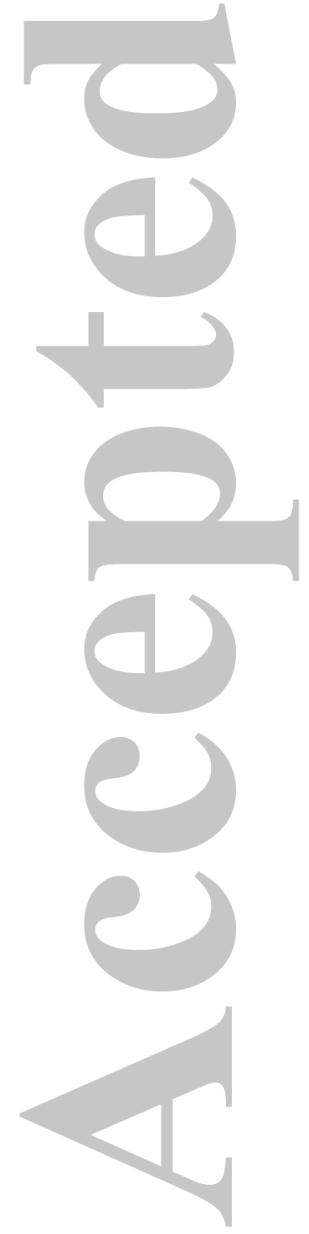


A numerical investigation and experimental verification of size effects in loaded bovine cortical bone

J.C. Frame, M.A. Wheel \& P.E. Riches

Graphical Abstract

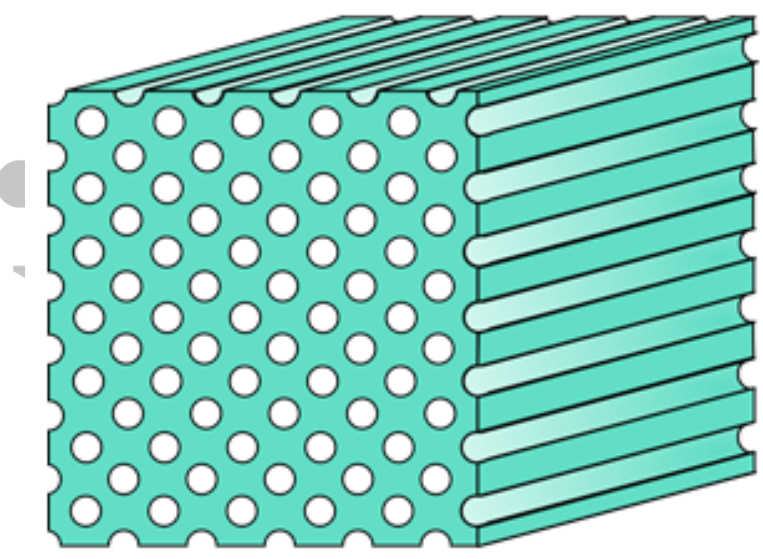

(a)

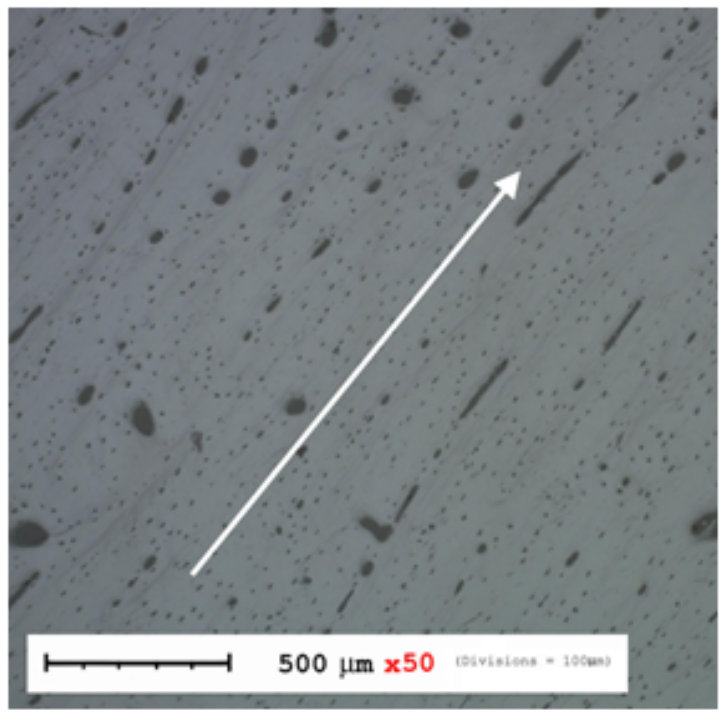

(c)

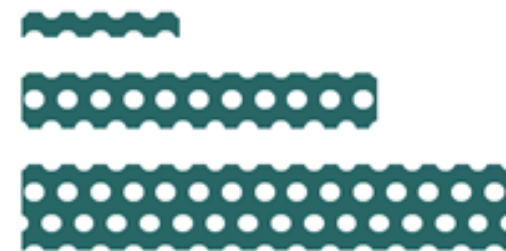

$\bullet \bullet \bullet \bullet \bullet \bullet \bullet \bullet \bullet \bullet \bullet \bullet \bullet \bullet \bullet \bullet \bullet \bullet \bullet \bullet$

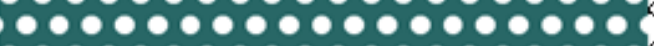

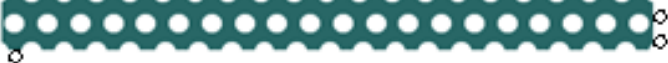

(b)

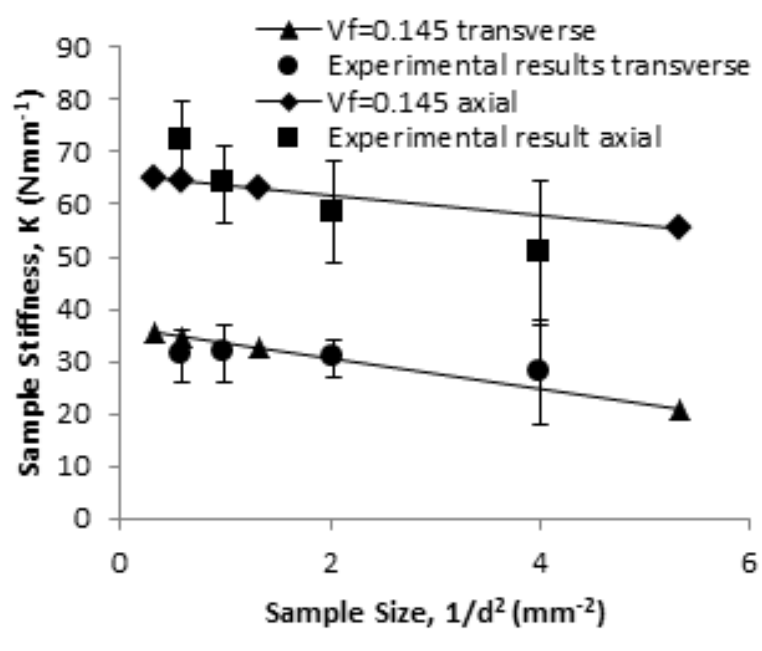

(d)

An idealized representation of cortical bone (a) incorporating the major microstructural feature, the vascular channel or Haversian canal system, has been used to generate finite element models of different sizes (b) that are loaded in bending. The surface morphology of the models reflects that of bone samples (c) where the exposed channels are evident. Samples (c) and FE models (b) both exhibit increasing compliance with decreasing beam depth (d), a paradoxical size effect not forecast by more generalized continuum theories. 